\title{
Current Trends in E-commerce Development in Hospitality
}

\author{
PhD candidate Alexander Dimitrov \\ University of Economics - Varna, Varna, Bulgaria \\ alexander.dimitrov@ue-varna.bg
}

\begin{abstract}
Object of study in this report are the technological innovations in electronic commerce and the opportunities for growing the sales in the hotels. Following the trend that more and more people are using Internet for shopping and therefore to book their reservation online, there will be outlined the key current trends in e-commerce development. The report is based on the actual innovations such as mobile commerce and the expectations that most of electronic sales during the upcoming years will be through mobile devices; chatbots and the opportunity for optimizing the operational workload; alternative payment methods, which are becoming more preferable when finalizing the sales.
\end{abstract}

Key words: electronic commerce, hospitality, trends, m-commerce, payment methods

JEL Code: O00; doi:10.36997/IJUSV-ESS/2019.8.3.119

\section{Въведение}

Значението на електронната търговия за разрастване на продажбите на даден продукт, в частност и на хотелиерския, е от изключително важност в днешно време. Това е така заради променящите се навици на потребителите и ориентирането им към пазаруването онлайн. Доказателство за това е броят на хората, използващи интернет, който се повишава непрекъснато. Статистиката показва, че към 2015 година 39\% от световното население е онлайн, като процентът за САЩ, Западна Европа, Азия и Австралия е над 70, което очертава сериозна аудитория и налага хотелиерите да обрьщат сериозно внимание на електронното разпределение на капацитета си. В допълнение, младото поколение дава сериозна заявка да бъде обвързано с Мрежата. Над 25\% от поколението Y (познати също и като millennials) непрекъснато търсят и прилагат технологичните въведения. (Dabeva \& Lukanova, 2017)

Наред с нарастването на броя на онлайн потребителите, съвсем логично се повишават и пазаруващите в интернет. По данни на Statista, през 2015 година над 1,46 млрд. души са пазарували онлайн, като ръстът на тази бройка година след година с повече от 100 милиона потребители. През 2020 година се очаква над 2 милиарда от световното население на прави покупки онлайн. (eMarketer, 2007)

Оттук необходимостта от адаптиране към актуланите трендове в електронната търговия е неизбежна, особено за динамичен бизнес, какъвто е туризмът и в частност хотелиерството. Също така, големият брой на онлайн потребителите и техните навици също следва да се вземат под внимание от опериращите в заведенията за пребиваване. В доклада ще бъдат представени някои от съвременните тенденции, които оказват ключова роля в развитието на световната електронна търговия. Сред тях са мобилната търговия, която като част от е-тьрговията разраства все повече дела си, особено сред поколението Ү и през следващите години смартфоните ще имат превес като предпочитан начин за общуване и правене на резервация; изкуственият интелект, в частност чат ботовете, които помагат за навременната информираност на гостите и оптимизират оперативната работа; алтернативните методи на плащане, които пък играят важна роля при последната стъпка преди финализирането на сделката, в случая - резервацията.

\section{Сыщност и роля на електронната търговия}

В документите на ООН е прието, че електронната търговия е „електронен обмен на данни за поддържане на търговски транзакции“. (Fomerand, 2009) От международната организация добавят още, че тя влияе върху всички дейности, свързани с бизнеса и водещи 
до сключването на сделка. Тук са посочени над 15 дейности, като основните от тях са маркетинг и продажби, транспорт и снабдяване, автоматизирана продажба на електронни стоки и услуги и други.

В българското законодателство съществува Закон за електронната търговия от 2006 година. В него е записано, че тя представлява „предоставянето на услуги на информационното общество. Услуги на информационното общество са такива услуги, включително предоставяне на търговски съобщения, които обикновено са възмездни и се предоставят от разстояние чрез използването на електронни средства след изрично изявление от страна на получателя на услугата“. (Закон за електронната тьрговия, 2015)

Повечето специалисти в сферата на туризма не дават конкретно определение на електронната търговия в туризма, но маркират основните канали, по които преминават онлайн продажбите. Sezgin (Sezgin, 2016) пояснява, че достьпността на интернет сайтовете на различни устройства, мобилните комуникации и приложения, имейл, както и кол центровете формират завършеността на е-търговията в туризма.

От посочените по-горе дефиниции може да се изведе, че електронната търговия е специфичен тип бизнес отношения в туризма, които се провеждат чрез използването на информационни технологии. Целта на тези отношения е търгуването на туристически продукт, чиято доставка може да се извърши извън интернет пространството. Според Моцев (Моцев, 2001) е-тьрговията не представлява само продажби чрез Интернет - тя обединява участниците в електронните пазари, добавя стойност и повишава ефективността на търговската дейност като цяло. Чрез нея разходите могат да се намалят, което води до предлагане на продукти и услуги с по-ниски цени.

Няколко са предимствата, които правят електронната търговия по-предпочитана пред традиционната (офлайн) търговия:

- достьпност навсякъде и по всяко време - 24 часа, 7 дни в седмицата;

- предлагане на разнообразие от стоки и услуги;

- олекотен дизайн и лесен начин на ползване;

- възможност за проактивно привличане на клиенти посредством маркетингови кампании и ексклузивни лоялни програми.

Наред с посочените предимства, броят на хората, които имат достьп до интернет, продължава да расте. По данни на Международния телекомуникационен съюз, само за последните 15 години броят на интернет потребителите се е покачил осемкратно - от 400 милиона през 2000 година до 3,2 милиарда през 2015 година. (International Telecommunication Union, 2016) От най-актуалният доклад на съюза, към 2018 година за пръв път над 50\% от световното население има онлайн достьп. Това е двоен ръст в сравнение с относителния дял преди 10 години. По-осезаем е дельт в развитите страни, където близо $81 \%$ от хората там сърфират в интернет. За територията на нашата страна, през 2008 г. 39,7\% от всички българи са с онлайн достъп. Десет години по-късно почти $2 / 3$ (или 64,8\%) от всички живеещи в България са с достъп до Мрежата. (International Telecommunication Union, 2019) На фиг. 1 е посочен делът на индивидуални потребли, имащи достъп до интернет, в последните 18 години.

Бъдещите поколения също се очаква да бъдат привързани към Мрежата. В подкрепа на това твъдение е делът на младото поколение (15-24 години), което има достьп до интернет. Към 2017 година 70\% от младежите са сьрфирали онлайн. В развитите страни цифрите са още по-внушителни. Там 94\% от всички млади хора прекарват част от времето си зад монитора. (International Telecommunication Union, 2018) Всички тези данни потвърждават тенденцията, че все повече хора ще прекарват времето си в интернет и респективно биха пазарували онлайн. Това от своя страна информира за необходимостта от изграждане на онлайн стратегия на компаниите, и в частност на хотелите, за да бъдат по-успешни на пазара и да привличат повече клиенти и гости. Търсенето на хотел онлайн е по-достъпно от всякога, 
а процесьт по правене на резервации - по-опростен. Затова е необходимо да се следват актуалните тенденции в електронната търговия.

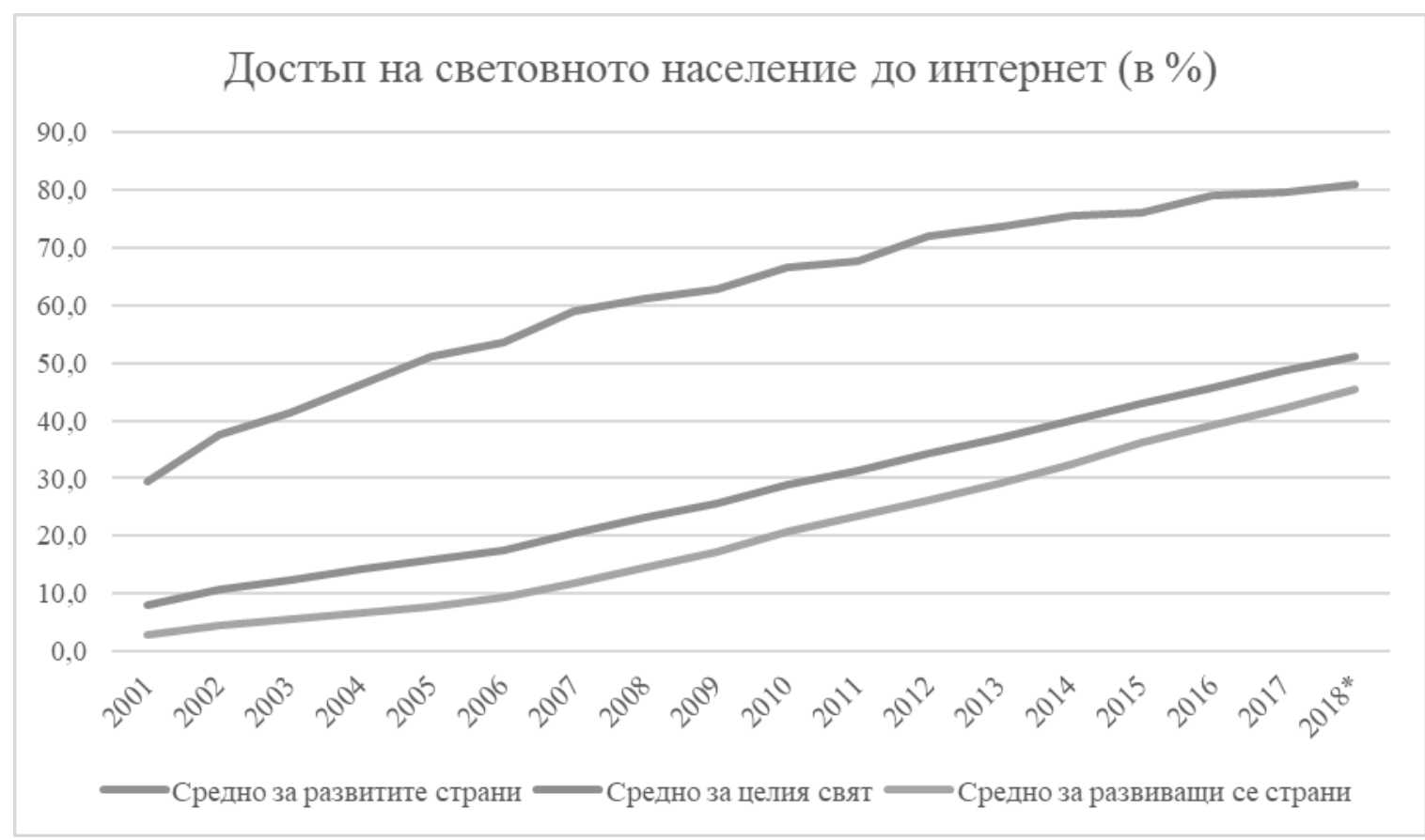

Фиг. 1 Относителен дял на достьпа на световното население до интернет Източник: Международен телекомуникачионен съюз

Съвременни тенденции в развитието на електронната търговия в хотелиерството

Електронната търговия се развива с бързи темпове, а технологичните иновации съпьтстват нейното развитие. Всяко от нововъведенията е продиктувано както от поведението на потребителите, така и от определена нужда за хотелиера, а намирането на решение е възможност за оптимизиране на работния процес за бизнеса и олекотяване на процеса на покупка или резервация за потребителя. Така всяка една от страните в отношенията извлича ползи от онлайн преживяването. Три от водещите тенденции ще бъдат представени в следващите редове - изкуственият интелект (и в частност чат ботовете), мобилната търговия и

\section{Изкуствен интелект}

С развитието на технологиите и навлизането на автоматизацията в работния процес, част от оперативната и повтаряща се работа започва да се извършва от изкуствен интелект. В последните години най-разпознаваемата част от изкуствения интелект са чат ботовете и автоматизираният отговор.

Чатботьт е компютьрна програма, която провежда диалози с хората на техния естествен език. Разговорьт се доближава до стандартния такъв между хора, като се провежда чрез приложения за социални мрежи или чат-прозорец. Ботът е съставен от изкуствен интелект, притежаващ разработен алгоритъм, който анализира и възпроизвежда текста като човек. (Seal, 2019) В повечето случаи чатботовете помагат на хотелиерите в отговорите на базисни запитвания от госта по време на направата на резервация и в комуникацията преди настаняването в хотела. Така се гарантира обратна връзка на най-популярните въпроси по всяко време - 24 часа, 7 дни в седмицата. Това на практика прави впечатление на потенциалния гост, тъй като отговорьт му пристига незабавно. По-сложните въпроси, които изискват по-всеобхватно и точно обяснение, се изпращат към хотела. В този случай, персональт пък спестява от време, за да отговаря на едни и същи запитвания и се фокусира 
само към най-специфичните казуси. Най-често ботът се интегрира в социалните мрежи иплатформите за чат, като приложението Messenger на Facebook, Viber, както и на официалната уеб-страница на заведението за пребиваване.

Няколко са основните функции, които могат да изпълняват чат ботовете (World Hotels, 2018):

- информационен ичентър - ботът може да информира за основните удобства и услуги на хотела. Така гостьт може да разбере къде е местоположението на обекта, а също така и с какво разполага помещението, в което ще бъде настанен. Допълнително, потенциалните гости могат да се информират за цените и наличностите в определен период, какви туристически ресурси и заведения за хранене и развлечения има около хотела и как да прекарат свободното си време по най-ползотворен начин докато са в съответното място за настаняване;

профилиране на гостите и използването на специфични подходи. Това може да се направи с цел увеличаване на конверсията. Благодарение на бисквитките, които съдържат важна информация за поведението и предпочитанията на съответния потребител, може много по-лесно да се профилират гостите и да се постигнат добри резултати, които да дадат отражение в повишаване на продажби. По този начин специални предложения и оферти много по-лесно могат да достигнат до подходящата група от хора, които проявяват интерес към тях. Допълнително, правилното филтриране би спомогнало и за подобряване на обслужването, тъй като много лесно ще се разбира какво гостите харесват или какво не е подходящо за тях; кои са последните тенденции, от които се вълнуват и т.н. С персонализирания подход, от една страна би се повишило удовлетвореността на гостите, а също така и привличане на повече лоялни гости.

В хотелиерския бизнес, двете водещи онлайн туристически агенции в света Booking.com и Expedia имат свои ботове, които спомагат за по-бързо преминаване на процеса на резервация през техните платформи. (Marques, 2018) В България има компании за разработване на изкуствен интелект. Някои от независимите хотели вече се възползват от услугите. Един от най-масовите онлайн рецепционисти у нас e EVA (Electronic Virtual Assistant), който дава информация за мястото за настаняване и града на пет езика (български, английски, руски, испански и китайски). (Poryazova, 2019) Сред функциите, които поддържа са: възможност за направа на директна резервация в хотела; запазване на маса в ресторанта в определен час; онлайн регистрация по номер на резервация; услугите, които предлага хотельт; галерия със снимки за помещенията в мястото за настаняване; промоционални цени за определени периоди; възможност за оставяне на мнение след края на престоя. Интересно е да се отбележи, че ботьт може да „говори“ и да предстви всички предимства на хотела, които бяха представени по-горе, освен да води писмена комуникация на петте езика.

Чрез удобствата, които предлагат чат ботовете, могат да бъдат изведени следните предимства:

- $\quad$ Cпестяване на оперативната работа - На разположение са 24 часа, 7 дни в седмицата, като освен налични по всяко време, могат да спестят работа на обслужващия персонал с отговори на често задавани въпроси на момента;

- По-висока конверсия от преглеждания към резервации, благодарение на бързото отговаряне на въпросите и персонализираните предложения и оферти, които да стигнат до точния потребител в точното време;

- $\quad$ Повече директни резервации, ако ботьт е синхронизиран с всички платформи и социални мрежи, където е представен хотельт. Чрез комуникацията и обвързането с потенциалните клиенти, те много по-лесно могат да се превърнат в следващите гости на съотвеното заведение за пребиваване;

- $\quad$ Получаване на повече обратна връзка - след края на престоя чатботьт може да замести обичайните маркетингови кампании по написването на отзив за престоя на 
госта. Чрез проактивното говорене на “човешки" език много по-лесно може да се подтикне гостьт да остави коментар. Освен градивната критика, чрез която може да се подобри предлагания продукт, биха се увеличили и позитивните отзиви.

\section{Адаптиране към мобилните технологии}

Наред с иновациите в технологичен аспект, мобилните телефони стават и все поосезаема част от ежедневието на хората. На фиг. 2 са посочени изследвания на eMarketeer, цитирани от Statista, според които над 50\% от световното население има смартфон и може да сърфира онлайн оттам. (eMarketeer, 2015) Очакванията са през 2019 г. 2/3 от потребителите да притежавам мобилен телефон. Сред населението на България има леко изоставане в тази тенденция. Въпреки това, с всяка изминала година потребителите на смартфони и у нас стават все повече. (Statista, 2017)

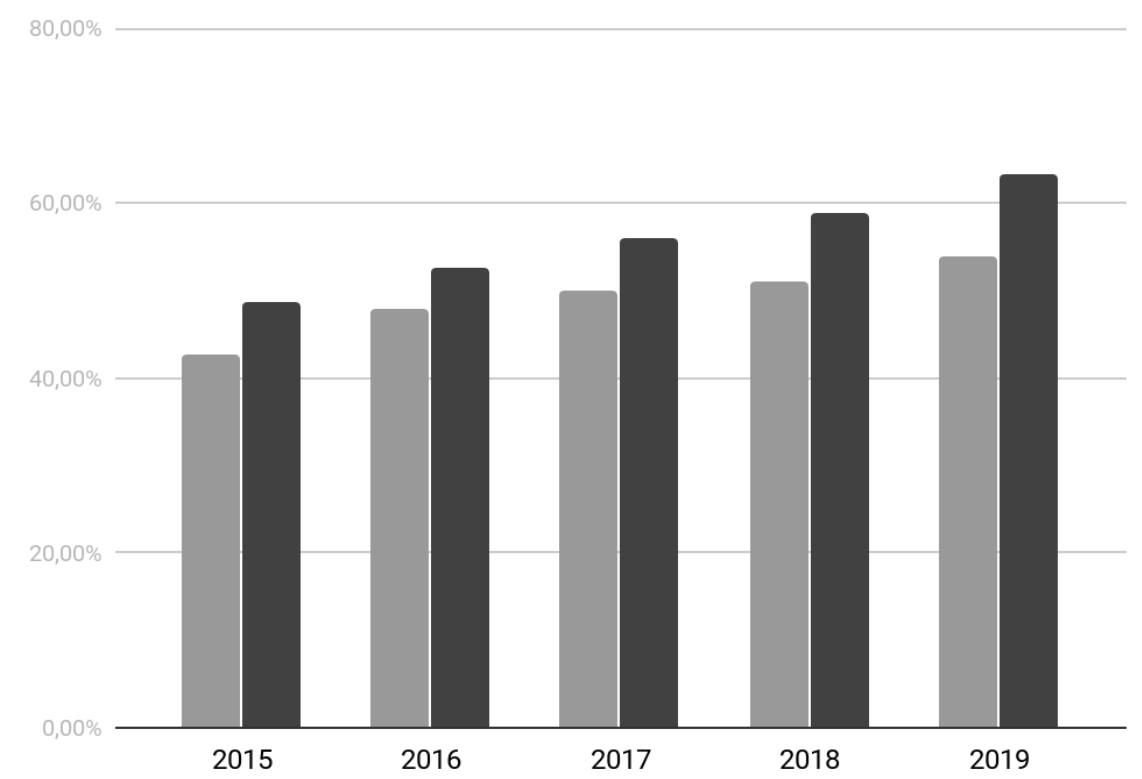

Фиг. 2 Относителен дял на потребителите на смартфони от населението в света и в България

Източник: eMarketeer, Statista

Като потвърждение на статистиката, че хората, ползващи смартфон, се увеличава с годините, е профильт на потребителя в САЩ. 98\% от поколение Y (или Milleannials), имат мобилен телефон. С процент по-малко са притежателите на възраст между 26 и 35 години. (Hakammer, 2017) В допълнение на това са и данните на GfK, които посочват, че 73\% от поколение Y ползват телефоните си и за пазаруване онлайн. Тези данни доказват, че мобилните устройства ще продължават да навлизат успешно в живота на хората, а още поосезаем е дельт на по-младите потребители. Оттам, благодарение и на благоприятната среда за развитие на продажбите онлайн и по-специално през мобилните приложения. Найосезаемото развитие на мобилната търговия става през 2008 година с появата на познатите в днешно време мобилни приложения, като в момента са налични на всички смартфони. По данни на Appfigures, VentureBeat, 10 години след старта, водещите магазини за мобилни приложения броят им е съответно 1,9 милиона в App Store за iOS, а в Google Play - над 2,4 милиона. (Appfigures, VentureBeat, 2019)

Първите пет хотелски вериги, които притежават най-голям брой стаи в портфолиото си (Wyndham, Marriott, Hilton, Accor, InterContinental Hotels Group), разполагат с добре разработени мобилни приложения, чрез които с един клик може да се намери информация и да се резервира хотел от портфолиото на бранда. В стремежа си да отговорят на непрестанно 
повишаващия се интерес към мобилните устройства, веригите обновяват и добавят нови функции, които са налични през смартфоните. По този начин потребителите могат да се възползват от тях и без да минават през рецепция. Основните функционалности, които са налични към момента в петте вериги са:

- Резервиране през мобилния телефон - освен информация за удобствата и услугите, потребителите могат да направят резервация за своя престой в хотелите от дадения бранд. Това е най-базовата функция, която е налична в приложенията и на петте хотелски вериги и чрез която могат да се увеличат приходите в заведението за пребиваване.

- $\quad$ Buртуален check-in/check-out - все повече отпада необходимостта от физическа регистрация при настаняване. Още повече удобства са налични и в част от хотелите. В четири от петте вериги е възможно това да стане виртуално, като дори в приложението е налична и виртуална ключ-карта, което замества физическата такава. B Hilton, Accor, InterContinental Group е възможно да се получи и фактура за престоя без намесата на персонал.

- $\quad$ Възможност за допълнителни услуги и рум сървиз - услугата е достъпна в три от веригите. B Hilton поръчката на рум сървиз може да се направи както по време на престоя, така и преди него, благодарение на опцията за точен час на доставка. В Accor пък е възможно да се резервира бизнес зала както за самостоятелно ползване, така и за бизнес среща. Следващи еко политиката, в определени хотели на Marriott e възможно да се откаже камериерска услуга.

- Предимства на лоялна програма - всички хотели са заложили и специални предимства за членовете на своите лоялни програми. Приложенията на Marriott и Hilton дори носят името на тези програми. Освен точките, които се трупат при резервирането на нощувки, са налице и опции за безплатен ьпгрейд и специални оферти, налични за редовните гости на съответните брандове.

На таблица 1 са посочени кои от веригите поддържат определените функционалности през мобилното си приложение. Прави впечатление, че повече екстри предлагат веригите, които имат в портфолиото си хотели от висок клас. По този начин - предлагайки разнообразие от продукти и удобства на своите гости, а от друга страна и интегрирайки ги бързо и преди всички други, това им гарантира още по-голяма лоялност и привличане на поплатежоспособни гости.

Таблица 1. Функционалности на мобилните приложения във водещите световни вериги

\begin{tabular}{|l|c|c|c|c|c|}
\hline & $\begin{array}{c}\text { Резервиране } \\
\text { пре3 } \\
\text { телефон }\end{array}$ & $\begin{array}{c}\text { Check-in } \\
\text { / Check- } \\
\text { out }\end{array}$ & $\begin{array}{c}\text { Допълнителни } \\
\text { услуги }\end{array}$ & $\begin{array}{c}\text { Рум } \\
\text { сървиз }\end{array}$ & $\begin{array}{c}\text { Свързаност с } \\
\text { лоялна } \\
\text { програма }\end{array}$ \\
\hline $\begin{array}{l}\text { Marriott } \\
\text { International }\end{array}$ & Да & Да & Да & Да & Да \\
\hline Hilton & Да & Да & Да & Да & Да \\
\hline Accor & Да & Да & Не & Не & Да \\
\hline IHG & Да & Не & Не & Не & Да \\
\hline Wyndham & & & \multicolumn{1}{|l}{ Да } \\
\hline
\end{tabular}

Източник: Таблицата е съставена от автора 
С нарастващия брой на хората, които притежават мобилни телефони и респективно резервират по този начин, мобилната търговия навлиза и става все по-важна част от бизнеса. Като предимства от тази тенденция могат да се изведат (Dimitrov, 2019):

Привличане на повече лоялни гости. Чрез ексклузивните цени и придобивки могат да се привлекат нови почитатели към съответния компания. Наличието на мобилно приложение още повече увеличава привързаността на потребителя към бранда. Това е така, защото веднъж инсталирано, то присъства в телефона по всяко време и чрез известията за новости много по-лесно даденият хотел може да достигне до съответния гост;

Гъвкавост в иенообразуването и достигане до нови таргет групи. Ексклузивните цени и оферти през мобилно устройство водят до по-голяма гъвкавост в ценообразуването на хотела, като по този начин това би спомогнало за повишаване на заетостта основно в последната минута и популяризирането на дадения бранд сред младата аудитория, която споделя все по-голяма част от времето си през смартфона и пазарува найчесто онлайн.

Бързина в обслужването и по-висока удовлетвореност у гостите. Често опашките при регистрация в хотела и изчакването за зареждане на стаята изнервят гостите и това си оказва влияние върху цялостното им впечатление за престоя. С виртуалните карти гостите могат директно да избират в коя стая да отседнат, да получат известие кога тя е заредена и директно да влязат в нея. От друга страна, благодарение на историята на дадения гост и неговото поведение в резервирането, чрез мобилното устройство много по-лесно могат да се персонализират неговите навици и по по-лесен начин той да открие следващото си пътуване.

\section{Онлайн плащания и алтернативни методи на разплащане}

Основна роля при финализирането на „сделката“ онлайн оказват методите на разплащане. Освен с възможността за плащане на място при настаняване, по-голямата част от хотелите изискват опция за предплата или гарантиране на резервацията още при направата ѝ. Затова възможностите, с които гостите могат да платят, са от изключителна важност за завършване на резервацията.

Още с основаването на е-търговията, електронните плащания започват да набират скорост. Ако преди години те са били пожелателни, то днес приемането на всякакви методи на разплащане биха допринесли за повече постъпления и нови клиенти. (Qin, Z. et al, 2014) Освен стандартните кредитни карти и плащането в кеш, налице са и алтернативни плащания. Това представят тези методи, които са използвани за алтернатива на картовите разплащания, като дигитални портфейли, чекове, мобилни разплащания. Последните добиват популярност през това десетилетие и се използват предимно в Азия и Европа. (Banking Circle, 2019)

Някои от алтернативните плащания се използват в определени страни и са популярни сред местното население. Така например, като част от най-популярните глобални алтернативни начини за разплащане са PayPal, Apple Pay, Stripe. Има и методи с голям пазарен дял сред местните хора. Това са AliPay и WeChat Pay в Китай и iDeal в Холандия. През 2019 година се очаква чрез алтернативните начини за плащане да преминат над 55\% от транзакциите в електронната търговия. (Dooley, 2019) Поради нарастващия им дял, вече има специализирани доставчици и банкови институции, които предават опция за виртуалните плащания. Хотелите също така могат да се възползват и от тази услуга през водещите платформи за онлайн резервации. Освен че се очаква тези алтернативни плащания да навлязат още повече в ежедневието на както на потребителите, така и на бизнеса, те носят и 
доста предимства. Сред тях са:

увеличаване на обема на резервациите - с приемането на различни методи за плащания, гостите могат да платят по удобния за тях начин;

- по-голяма сигурност на приходите - повечето електронни плащания имат специални защити, които могат да спестят оспорването на транзакциите;

привличане на определни националности - в някои държави, като Китай, пазарният дял на местните методи за разплащане е доста висок. Това е възможност, чрез която предлагането на опцията може да привлече гости от съответната страна, когато те търсят място за настаняване в даден хотел в Европа например.

\section{Заключение}

Онлайн пространството вече е предпочитано място за получане на информация и направата на резервация. Затова и хотелиерите, освен с възможността да представят своя обект в интернет и да разсрастват приходите си посредством електронната търговия, е необходимо да се адаптират да актуалните тенденции. Това от една страна би оптимизирало оперативната работа и фокусиране върху останалите важни моменти от работното ежедневние, а от друга страна - би помогнало и на потребителите да ги намерят и резервират по по-лесен начин. Това става с наличието на изкуствен интелект, който да се интегрира в работната среда и онлайн платформите; с адаптиране към мобилната търговия, която става все по-предпочитан канал на резервиране в световен мащаб; и възможности за алтернативни плащания, с които да се отговори на навиците на всеки един потенциален гост, с цел - посигурен и по-приятен престой.

\section{References}

1. Appfigures, VentureBeat. (2019). Number of apps available in leading app stores as of 3rd quarter 2019. Statista. Statista Inc. [Online] Available from:

https://www.statista.com/statistics/276623/number-of-apps-available-in-leading-app-stores/ [Accessed: 15/09/2019]

2. Banking Circle. (2019) What are alternative payment methods. [Online] Available from: https://www.bankingcircle.com/what-are-alternative-payment-methods-027964 [Accessed: 15/09/2019]

3. Dabeva, T., G. Lukanova (2017). Hotelierstvo. Varna: Nauka I ikonomika.

4. Dimitrov, A. (2019) Predimstva na mobilnata targoviya (m-commerce) v savremennoto hotelierstvo. International Scientific-Practical Conference: Tourism In The New Millennium State and Prospects. Svishtov, October $11^{\text {th }}-12^{\text {th }} 2019$, Bulgaria, pp.525-532

5. Dooley, J. (2019). Why Alternative Payment Methods are Shaping the Future of E-commerce. [Online] Available from: https://www.klarna.com/knowledge/articles/why-alternative-paymentmethods-are-shaping-the-future-of-e-commerce/ [Accessed: 17/09/2019]

6. eMarketeer (2015): Mobile phone internet user penetration worldwide from 2014 to 2019. [Online] Available from: https://www.statista.com/statistics/284202/mobile-phone-internetuser-penetration-worldwide/ [Accessed: 15/09/2019]

7. eMarketer. (2017). Number of digital buyers worldwide from 2014 to 2021 (in billions). Statista. Statista Inc. [Online] Available from: https://www.statista.com/statistics/251666/number-of-digital-buyers-worldwide/ [Accessed: 15/09/2019]

8. Fomerand, J. (2009). The A to $\mathrm{Z}$ of the United Nations. London: Scarecrow Press. 
9. Hankammer, S. (2017). Customization 4.0. Springer.

10. International Telecommunication Union (2016). ITC - Fact and Figures 2015. [Online] Available from: https://www.itu.int/en/ITU-D/Statistics/Documents/facts/ICTFactsFigures 2015.pdf [Accessed: 01/07/2019]

11. International Telecommunication Union (2018). ITC - Fact and Figures 2017. 2018. [Online] Available from: https://www.itu.int/en/ITU-D/Statistics/Documents/ facts/ICTFactsFigures2017.pdf [Accessed: 01/07/2019]

12. International Telecommunication Union (2018). ITU releases 2018 global and regional ICT estimates. 2018. [Online] Available from: http://www.itu.int/en/ITUD/Statistics/Pages/definitions/regions.aspx.html [Accessed: 01/07/2019]

13. Marques, M. (2018) Top 3 chatbots that are changing the travel industry. [Online] Available from: https://medium.com/hijiffy/top-3-chatbots-that-are-changing-the-travel-industryd325082c50b8 [Accessed: 15/09/2019]

14. Motsev, M. (2001). Elektronna targoviya.Sofia: ForKom.

15. Poryazova, V. (2019). Изкуствен интелект смени служител в пловдивски хотел. [Online] Available from: https://www.marica.bg/izkustven-intelekt-smeni-sluzhitel-v-plovdivski-hotelArticle-233257.html [Accessed: 15/09/2019]

16. Seal, P. (2019). Guest Retention Through Automation: Ana Analysis of Emerging Trends in Hotels in Indian Sub-Continent. // Global Trends, Practices, and Challenges in Contemporary Tourism and Hospitality Management.

17. Sezgin, E. (2016). E-Consumers in the Era of New Tourism. Eskisehir: Springer.

18. Statista. (2017). Forecast of smartphone user numbers in Bulgaria from 2015 to 2022 (in million users). Statista. Statista Inc. [Online] Available from: https://www.statista.com/statistics/566061/predicted-number-of-smartphone-users-in-bulgaria/ [Accessed: 15/09/2019]

19. Qin, Z., Y. Chang, S. Li, F. Li. (2014). E-Commerce Strategy. Springer

20. Woldhotels.com (2018). Chatbots: The Impact on the Hotel Industry. [Online] Available from: https://www.worldhotels.com/articles/chatbots-the-impact-on-the-hotel-industry [Accessed: 15/09/2019]

21. Zakon za elektronnata targoviya, 2015 